\title{
Benefit-Risk Analysis of Buprenorphine for Pain Management
}

\author{
Martin Hale ${ }^{\prime}$ \\ Mark Garofoli (iD) ${ }^{2}$ \\ Robert B Raffa ${ }^{3,4}$ \\ 'Gold Coast Research, LLC, Plantation, FL, \\ 333।7, USA; ${ }^{2}$ Department of Clinical \\ Pharmacy, West Virginia University School \\ of Pharmacy, Morgantown, WV, 26505, \\ USA; ${ }^{3}$ University of Arizona College of \\ Pharmacy, Tucson, AZ, 8572I, USA; \\ ${ }^{4}$ Department of Pharmaceutical Sciences, \\ Temple University School of Pharmacy, \\ Philadelphia, PA, 19140, USA
}

Correspondence: Robert B Raffa Email robert.raffa@gmail.com

\begin{abstract}
Health care providers in the United States are facing challenges in selecting appropriate medication for patients with acute and chronic pain in the midst of the current opioid crisis and COVID-19 pandemic. When compared with conventional opioids, the partial $\mu$-opioid receptor agonist buprenorphine has unique pharmacologic properties that may be more desirable for pain management. The formulations of buprenorphine approved by the US Food and Drug Administration for pain management include intravenous injection, transdermal patch, and buccal film. A comparison of efficacy and safety data from studies of buprenorphine and conventional opioids suggests that buprenorphine may be a better-tolerated treatment option for many patients that provides similar or superior analgesia. Our benefit-risk assessment in this narrative review suggests that health care providers should consider that buprenorphine may be an appropriate alternative for pain management over other opioids.
\end{abstract}

Keywords: buprenorphine, buprenorphine buccal film, analgesia, pain, opioids

\section{Introduction}

As a result of the current opioid crisis, the United States is having difficulty providing adequate care for patients with acute and chronic pain. ${ }^{1}$ Statistics from 2016 indicate that acute pain is reported by approximately 55\% of hospitalized patients, and 50 million $(20.4 \%)$ adults in the United States have chronic daily pain, with 19.6 million (8\%) experiencing high-impact chronic pain that interferes with daily life or work activities. ${ }^{2}$ Immediate-release/short-acting or extended-release (ER)/long-acting opioids are often prescribed for pain, as they elicit analgesia by acting on opioid receptors to inhibit nociceptive stimulation. ${ }^{3}$ Increased prescribing rates coupled with the diversion of prescription opioids have contributed to the national crisis of opioid use disorder (addiction) and overdose deaths, signifying the need for safer alternatives. ${ }^{4}$ Although abusedeterrent opioid formulations were designed to deter altered routes of administration (eg, snorting, inhalation, chewing, injection) that increase the risk of overdose, these formulations are not abuse-proof..$^{5}$ With advancing better practices in response to the opioid crisis, 17 of the 38 states with prescription opioid overdose death data saw a decline between 2017 and 2018, and no states experienced a significant increase. ${ }^{4}$ However, opioid abuse rates have increased with the COVID-19 pandemic. $^{6}$

Opioids can be divided into conventional opioids (full $\mu$-opioid receptor agonists such as fentanyl, hydrocodone, morphine, oxycodone $)^{7}$ and mixed-action or atypical 
opioids (such as buprenorphine, butorphanol, tramadol, tapentadol). ${ }^{3}$ When compared with other opioids currently on the market, the atypical opioid buprenorphine has a unique pharmacologic profile. ${ }^{8}$

Buprenorphine is a partial agonist with very high binding affinity at $\mu$-opioid receptors, an agonist with low binding affinity at the nociceptin opioid receptor (NOP, formerly known as opioid receptor like-1), and an antagonist with high binding affinity at $\kappa$ - and $\delta$ opioid receptors (Figure 1). ${ }^{9}$ The term "partial agonist" was applied owing to a partial effect on stimulating the receptor with in vitro assays. ${ }^{10}$ This does not necessarily translate to partial analgesic efficacy in vivo or in clinical practice, as the analgesic signaling pathway may be sufficiently activated by a partial agonist. Partial agonism at the $\mu$-opioid receptor by buprenorphine yields potent analgesia and a ceiling effect on respiratory depression and euphoria and reduces other adverse events commonly observed with conventional opioid use. ${ }^{10-16}$ Buprenorphine does not occupy all $\mu$-opioid receptors, which allows for efficacy of concomitant full $\mu$-opioid receptor agonists. ${ }^{9}$ Antagonism at the $\delta$ - and $\kappa$-opioid receptors may limit constipation, respiratory depression, dysphoria, and substance abuse. ${ }^{9}$ Kappa-opioid receptor antagonists are currently being considered as promising therapeutics for psychiatric conditions such as depression, anxiety, and substance abuse disorders. ${ }^{17}$ Agonism at NOP contributes to spinal analgesia and may limit the potential for substance abuse and tolerance commonly observed with full $\mu$-opioid receptor agonists.
Conventional opioids bind to $\mu$-opioid receptors, which activate signaling pathways that depress neural functions and are associated with adverse events. However, the partial agonistic effects of buprenorphine limit $\mu$-opioid receptor activity, which elicits analgesia pathways but may restrict pathways associated with adverse events, contributing to a more favorable safety profile and patient satisfaction.

Buprenorphine is approved by the US Food and Drug Administration (FDA) for acute pain, chronic pain, opioid use disorder, or opioid dependence, depending on the formulation (Table 1). ${ }^{7,18}$ Buprenorphine formulations exist as either a combination therapy with naloxone (eg, Suboxone and similar products) or as stand-alone products. The stand-alone buprenorphine products and their indications are listed in Table 1. ${ }^{19-26}$ Buprenorphine also exists as a suppository, but this formulation is not FDAapproved for use in the US. ${ }^{27}$

The purpose of this review is to present the literature assessing the efficacy of buprenorphine products for the treatment of pain and compare the risks and benefits of buprenorphine to conventional opioids. The information presented here can be used to aid health care professionals in medication selection for patients who are experiencing pain and for whom opioid treatment is deemed appropriate.

\section{Methods}

This narrative review is based on the authors' knowledge of the literature, their clinical experience, and literature searches including the terms buprenorphine and pain.

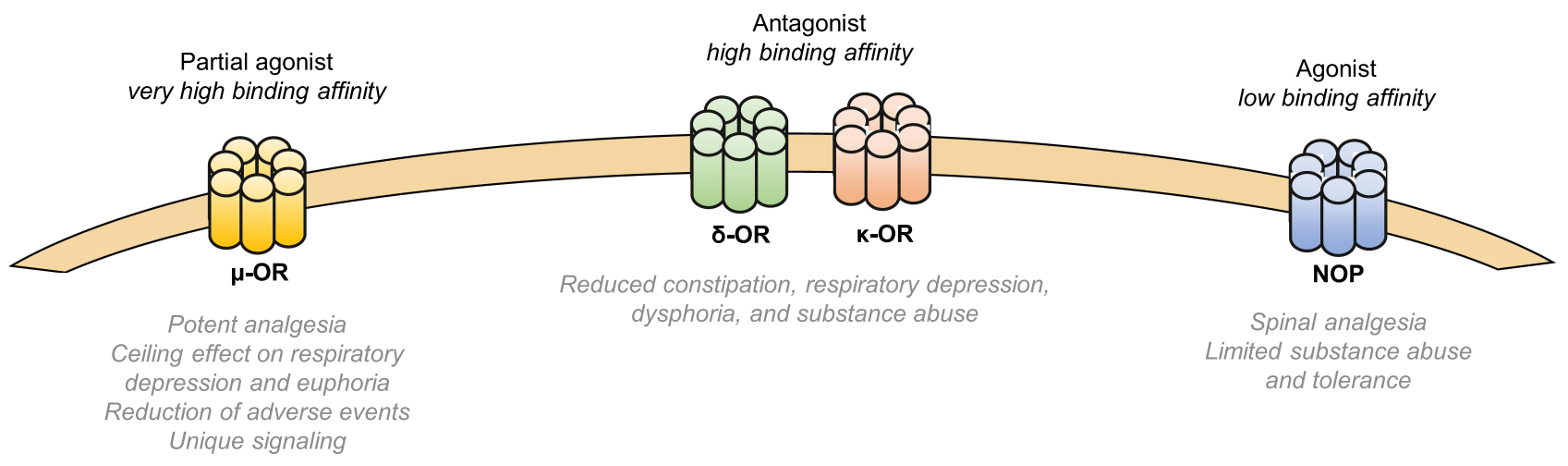

Figure I Mechanism of Action of Buprenorphine at Opioid and NOP Receptors. At $\mu$-opioid receptors, buprenorphine is a partial agonist with very high binding affinity, which results in potent analgesia, contributes to a ceiling effect on respiratory depression and euphoria, and reduces other adverse events commonly observed with opioid use owing to unique phosphorylation and signaling activity. Buprenorphine has antagonistic activity with high binding affinity at $\kappa-$ and $\delta$-opioid receptors, which may limit constipation, respiratory depression, dysphoria, and substance abuse. The agonistic activity and low binding affinity at the NOP receptor contribute to spinal analgesia and may limit the substance abuse potential and tolerance commonly observed with full $\mu$-opioid receptor agonists.

Abbreviations: NOP, nociceptin; OR, opioid receptor. 


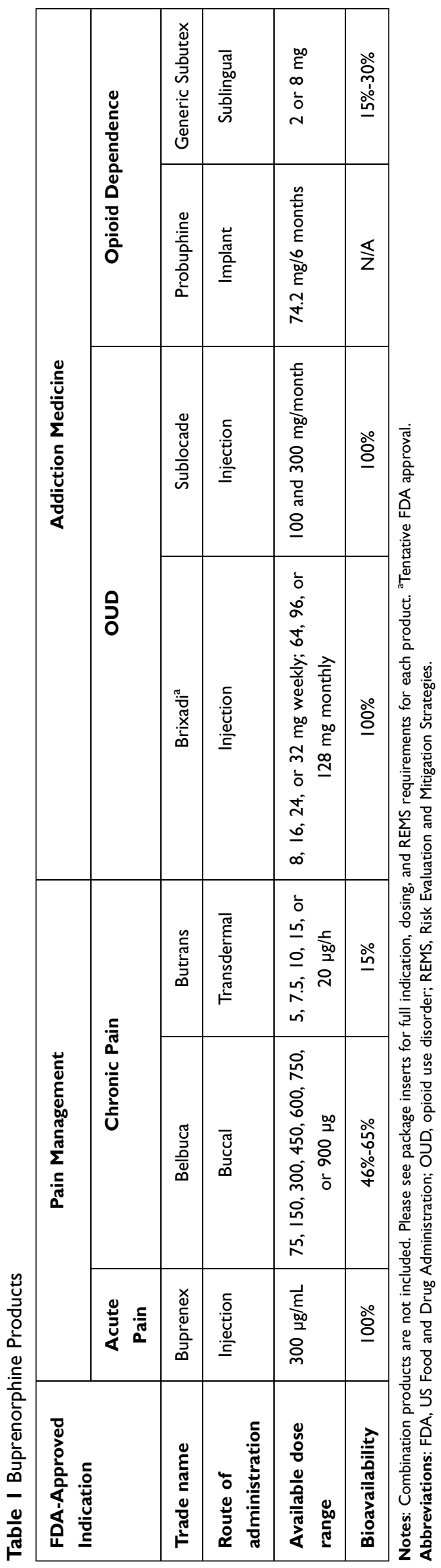

\section{Efficacy of Buprenorphine in Pain Management Intravenous (IV) Formulation}

Although IV buprenorphine has not been studied in chronic pain, this formulation has been shown to have a dose-dependent analgesic effect in patients with acute pain. ${ }^{28}$ IV buprenorphine had equal or superior analgesic efficacy to IV morphine for postoperative pain following abdominal, cardiac, lung, and spinal surgery or lateral thoracotomy. ${ }^{29-36}$ Bradley et al. found that 4 to $6 \mu \mathrm{g} / \mathrm{kg}$ IV buprenorphine following abdominal surgery (hysterectomy or cholecystectomy) provided more potent analgesia for a longer duration than morphine. ${ }^{29}$ In a separate study, administration of intrathecal morphine and IV buprenorphine together alleviated pain and minimized sedation more effectively than either drug separately, with IV buprenorphine reducing the number of side effects when compared with morphine. ${ }^{37}$ IV buprenorphine was also more effective than procaine for pain relief in patients with acute pancreatitis. ${ }^{38}$ In addition to providing effective pain relief, a low-dose infusion ( $25 \mu \mathrm{g} / \mathrm{h}$ for 24 hours) of buprenorphine prevented the short-term development of secondary hyperalgesia around postoperative surgical incisions. $^{33}$

\section{Sublingual (SL) Formulation}

Although SL buprenorphine is not indicated for chronic pain, a systematic review of 10 chronic pain trials $(6$ studies used $\leq 400 \mu \mathrm{g} /$ dose; 4 studies used $\geq 400 \mu \mathrm{g} / \mathrm{dose}$; the dose range across all studies was $0.1-32 \mathrm{mg}$ ), including for the treatment of general, osteoarthritic, sickle-cell disease, nociceptive, and cancer chronic pain in the general, elderly, or pediatric populations, found this formulation to be efficacious in $100 \%$ of the studies. ${ }^{39}$ For example, Malinoff et al. examined patients with chronic pain syndrome and found that pain decreased in $86 \%$ of patients following SL buprenorphine administration, and many patients reported improved mood, decreased sleep disturbance, and an improved sense of well-being after treatment. ${ }^{40}$ For acute pain, SL buprenorphine had similar or greater postoperative analgesic efficacy when compared with IV patient-controlled analgesia (morphine) or intramuscular morphine following surgery (Figure 2); however, significant relief was not observed until after 2 hours postdose, suggesting that IV buprenorphine may be more appropriate for immediate relief from severe acute pain. $^{41,42}$ SL buprenorphine $(0.4 \mathrm{mg})$ also produced 


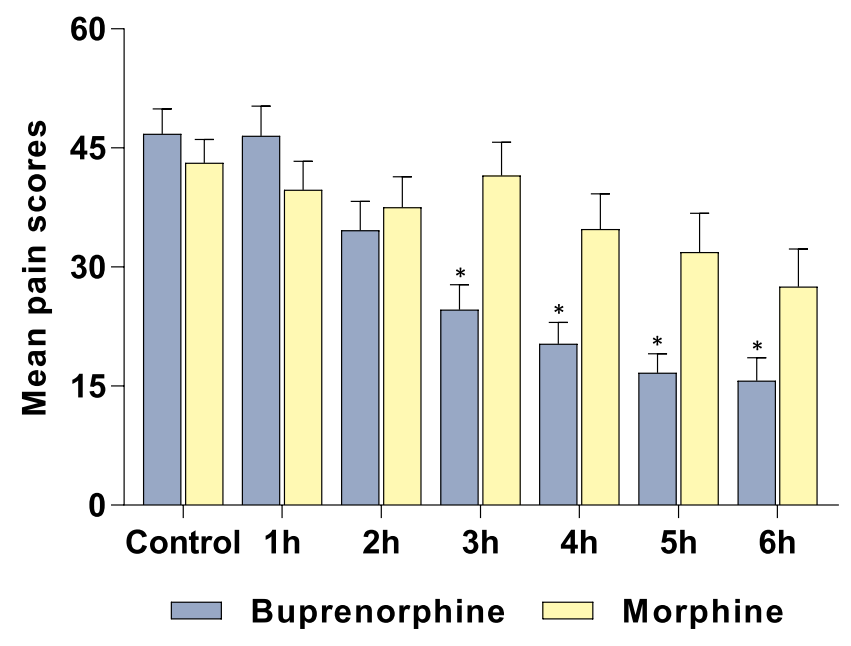

Figure 2 Pain Relief Induced by Intramuscular Morphine or Sublingual Buprenorphine Following Surgery. Pain scores were determined using a VAS after the administration of $0.4 \mathrm{mg}$ SL buprenorphine or an injection of $10 \mathrm{mg} / \mathrm{mL}$ morphine. ${ }^{*} p<0.05$ for comparisons between groups at that time.

Notes: Data from Edge et al (1979). ${ }^{41}$

Abbreviations: h, hour(s); SL, sublingual; VAS, visual analog scale.

analgesia equal to or greater than that produced by oral dihydrocodeine $(60 \mathrm{mg})$ in patients with postoperative pain. $^{43}$

\section{Transdermal Formulation}

In a systematic review, transdermal buprenorphine was found to be efficacious in $29(100 \%)$ clinical studies that examined chronic pain (general, low back, osteoarthritis, malignant, and musculoskeletal pain). ${ }^{7}$ The dosages of transdermal buprenorphine used in these chronic pain studies ranged from 5 to $140 \mu \mathrm{g} / \mathrm{h}$ (the highest available dosage strength in the United States is $20 \mu \mathrm{g} / \mathrm{h}$ ). Steiner et al. found that 12 weeks of treatment with transdermal buprenorphine resulted in significantly lower pain scores than placebo in opioid- naive patients with chronic low back pain. ${ }^{44} \mathrm{~A}$ multicenter randomized phase 4 trial by Corli et al. showed that transdermal buprenorphine had analgesic efficacy similar to that of transdermal fentanyl, oral morphine, and oral oxycodone in patients with cancer pain (Figure 3). ${ }^{45}$ In addition, transdermal buprenorphine has demonstrated efficacy in the treatment of postsurgical acute pain to a similar or greater extent than oral tramadol or tramadol/acetaminophen. ${ }^{46-48}$

\section{Buccal Film Formulation}

Buprenorphine buccal film (75 $\mu \mathrm{g}$ to $900 \mu \mathrm{g}$ ) has demonstrated analgesic efficacy in all currently published studies examining its effect on chronic low back pain (Figure 4). ${ }^{49-51}$ A retrospective analysis found that converting from a long-acting full $\mu$-opioid receptor agonist to buprenorphine buccal film provided continued analgesia in most patients despite a reduction in daily morphine milligram equivalent (MME) factor, which could lead to improved patient safety outcomes. ${ }^{52}$ To date, no studies have examined the effects of buprenorphine buccal film for acute pain, presenting a valuable opportunity for future research.

\section{Transdermal vs Buccal Film for Chronic Pain Management}

Among the formulations FDA-approved for chronic pain, buprenorphine buccal film has a higher bioavailability. Although buprenorphine has poor oral bioavailability and transdermal bioavailability is limited, the mucosa allows for higher bioavailability via the buccal route. ${ }^{9}$ Buprenorphine buccal film also has a larger available dose range compared to the transdermal patch, which may be preferable for some patients (Table 1). The $20 \mu \mathrm{g} / \mathrm{h}$ patch may not provide

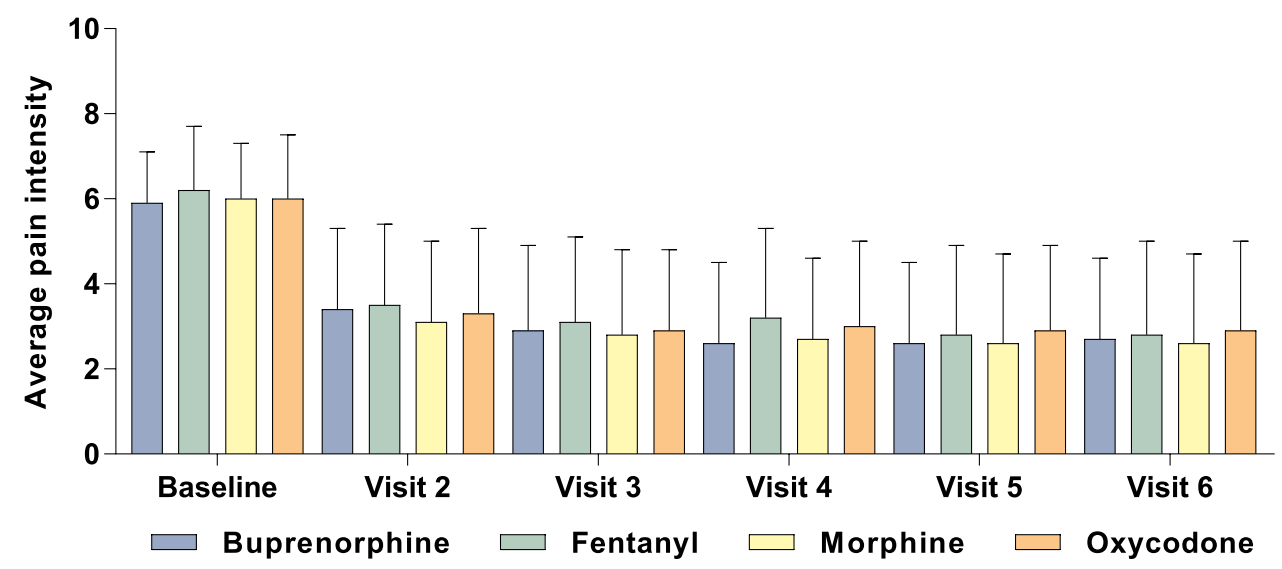

Figure 3 Efficacy of Transdermal Buprenorphine Compared With Conventional Opioids in Patients With Chronic Cancer Pain. Average pain intensity was measured on a numeric rating scale. Data are mean (SD). Data from Corli et al (2016). ${ }^{45}$ 

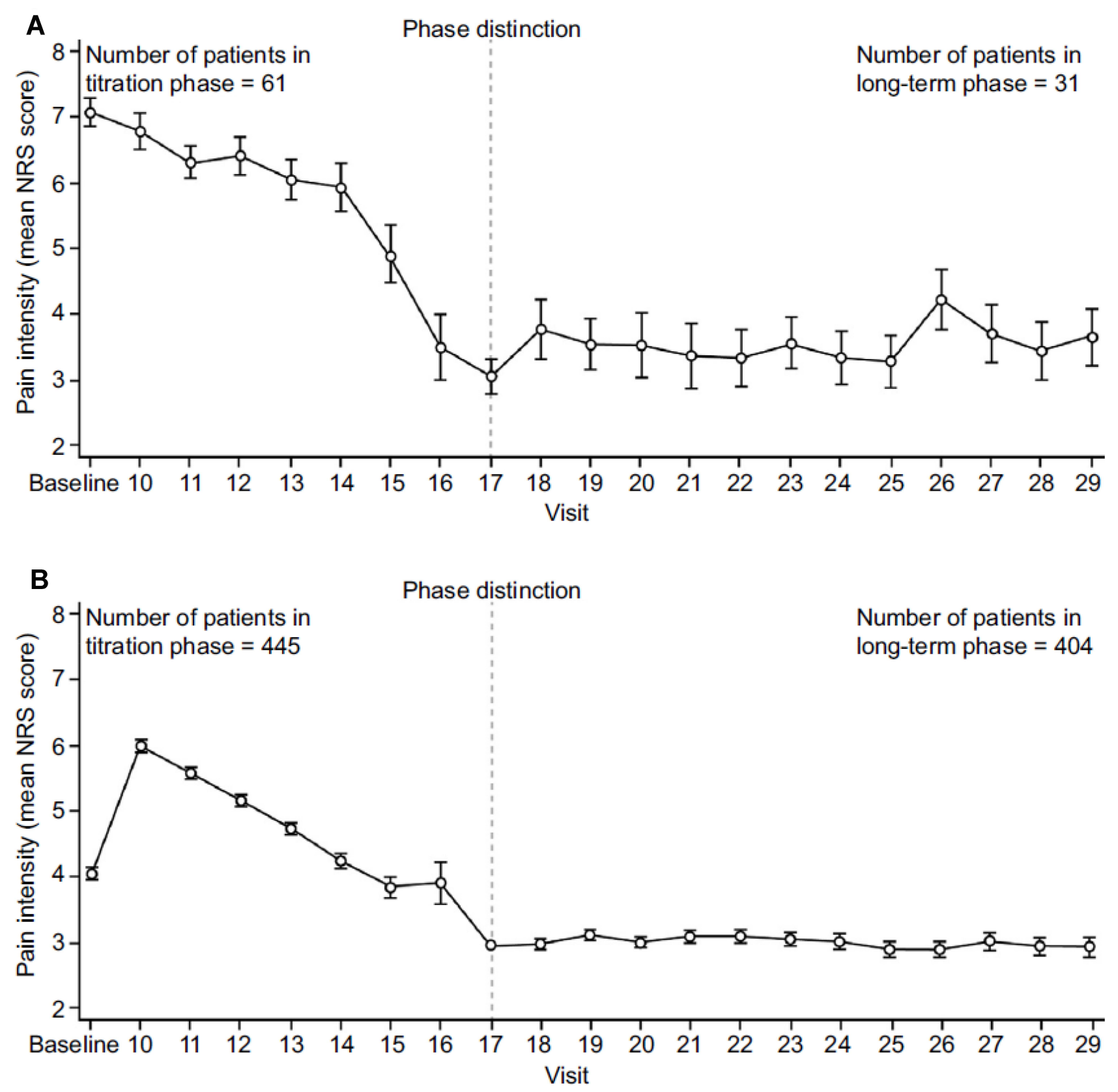

Figure 4 Efficacy of Buprenorphine Buccal Film in Patients With Chronic Low Back Pain. Mean NRS scores during the titration and long-term treatment phases with buprenorphine buccal film in (A) de novo patients and (B) rollover patients.

Notes: Copyright @2017. Dove Medical Press. Reproduced from Hale M, Urdaneta V, Kirby MT, Xiang Q, Rauck R. Long-term safety and analgesic efficacy of buprenorphine buccal film in patients with moderate-to-severe chronic pain requiring around-the-clock opioids. J Pain Res. 2017;10:233-240. ${ }^{50}$

Abbreviation: NRS, numerical rating scale.

adequate analgesia in patients receiving high-dose opioid treatment $\left(>80 \mathrm{mg}\right.$ MME factor/d). ${ }^{20}$ The dose range of buprenorphine buccal film (75-900 $\mu \mathrm{g})$ provides more flexibility to titrate to an optimal dose, making it a preferable option for patients whose needs exceed the doses available with the transdermal system. The highest dosage of transdermal buprenorphine available in the US is $20 \mu \mathrm{g} / \mathrm{h}$ (to be worn for 7 days), with the median equivalent dose of the buccal formulation being $300 \mu \mathrm{g} / 12 \mathrm{~h} .{ }^{53}$ Transdermal buprenorphine has the advantage of medication adherence with the ease of applying the product once a week, but it may also cause application site pruritus, erythema, and site rash, ${ }^{44}$ which are treatment-emergent adverse events not reported in clinical studies of buprenorphine buccal film. ${ }^{49-51}$ In 
clinical studies, $14 \%$ of patients with chronic pain discontinued transdermal buprenorphine owing to lack of perceived efficacy compared with $5 \%$ who discontinued buprenorphine buccal film for the same reason. ${ }^{7}$ In similar clinical trials, responder analysis of $\geq 30 \%$ or $\geq 50 \%$ reduction in pain intensity in opioid-experienced patients showed that the efficacy of buprenorphine buccal film was greater than transdermal buprenorphine (Figure 5). ${ }^{7}$ The buccal film also has the advantage of additional safety data, where comparison with a conventional opioid (immediate-release oxycodone) in a clinical study assessing respiratory drive showed that, unlike oxycodone, buprenorphine buccal film had no significant impact on respiration. ${ }^{54}$

\section{Benefit-Risk Assessment of Buprenorphine vs Conventional Opioids Efficacy}

Buprenorphine has a long-standing history of efficacy in postsurgical acute pain (IV formulation) and chronic pain (SL and transdermal formulations), and its clinical efficacy

A $\geq \mathbf{3 0} \%$ Reduction in Pain Intensity

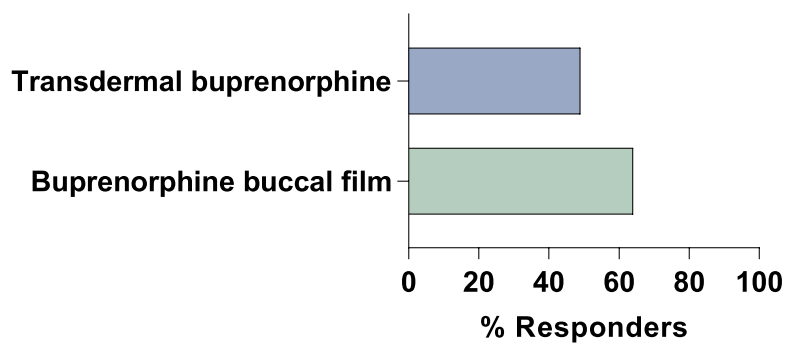

B

$\geq \mathbf{5 0 \%}$ Reduction in Pain Intensity

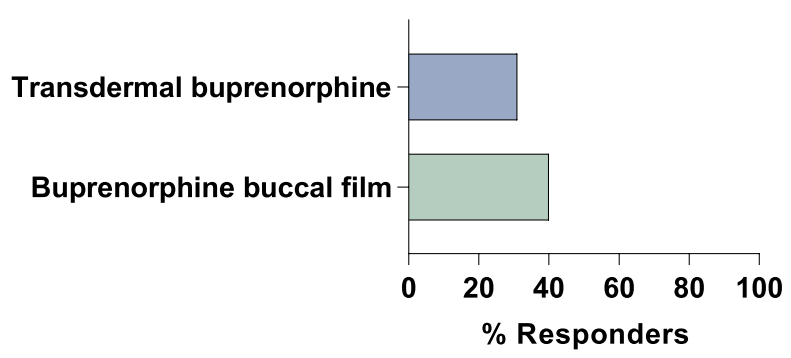

Figure 5 Efficacy of the Transdermal and Buccal Film Formulations of Buprenorphine. Responder analysis of similar opioid-experienced chronic pain clinical trials. Comparisons are of efficacy data for transdermal buprenorphine (20 $\mu \mathrm{g} / \mathrm{h})$ and buprenorphine buccal film (150-900 $\mu \mathrm{g} / / 2 \mathrm{~h})$ with response defined as (A) $\geq 30 \%$ or $(B) \geq 50 \%$ reduction in pain intensity.

Notes: Copyright @2019. Dove Medical Press. Adapted from Pergolizzi JV, Jr., Raffa RB. Safety and efficacy of the unique opioid buprenorphine for the treatment of chronic pain. J Pain Res. 2019;12:3299-3317. has been shown to be greater than that of morphine in some studies. ${ }^{29,39,44}$ Buprenorphine has been suggested to be 25 to 115 times more potent as an analgesic than morphine (depending on the study), with no ceiling effect on analgesia. ${ }^{9}$ Buprenorphine products no longer have an MME factor in the Centers for Disease Control opioid conversion guide, as they are not expected to be associated with overdose risk in the same dose-dependent manner as full $\mu$-opioid receptor agonists. ${ }^{55}$ In addition to morphine, the analgesic efficacy of buprenorphine has also been demonstrated to be equal to or greater than oxycodone (MME factor [mg]: 1.5) or fentanyl (MME factor for patch $[\mu \mathrm{g}]:$ 7.2) in chronic pain studies. ${ }^{45,55-58}$ When compared across clinical studies, the efficacy of buprenorphine buccal film was similar to that of the conventional ER opioids hydromorphone, hydrocodone, and oxymorphone. ${ }^{49,51,59-61}$ In a meta-analysis examining the effects of buprenorphine (SL, transdermal, and buccal) on chronic pain outcomes in patients with or without opioid use disorder (OUD), the authors found that efficacy was more pronounced in patients without OUD, and high doses may be needed for patients with OUD. ${ }^{62}$ Overall, the data from these studies suggest that buprenorphine has equivalent or greater clinical analgesic efficacy than conventional opioids.

\section{Safety}

Buprenorphine is a Schedule III drug with a unique mechanism of action that has less potential for abuse than Schedule II drugs (eg, morphine, oxycodone, fentanyl). ${ }^{63}$ The lower abuse potential of buprenorphine may mitigate the number of overdose deaths observed with conventional opioids. ${ }^{64}$ Opioids are commonly used recreationally and carry a high risk of diversion; therefore, choosing an opioid medication with slower absorption and less drug liking and abuse potential is imperative during the current opioid crisis. The risks of drug dependence and analgesic tolerance are also lower for buprenorphine than for conventional opioids. ${ }^{15,65,66}$

Buprenorphine also reduces the potential for respiratory depression and death compared with conventional opioids. $^{1,10,11}$ No cases of respiratory depression were reported in any clinical trials of buprenorphine buccal film. ${ }^{49-51}$ In a phase 1 study, buprenorphine buccal film 300,600 , or $900 \mu \mathrm{g}$ did not negatively impact respiratory drive, whereas oxycodone $30 \mathrm{mg}$ and $60 \mathrm{mg}$ significantly reduced respiratory drive (Figure 6). ${ }^{54}$ The clinical trials of buprenorphine buccal film included fewer than 1000 


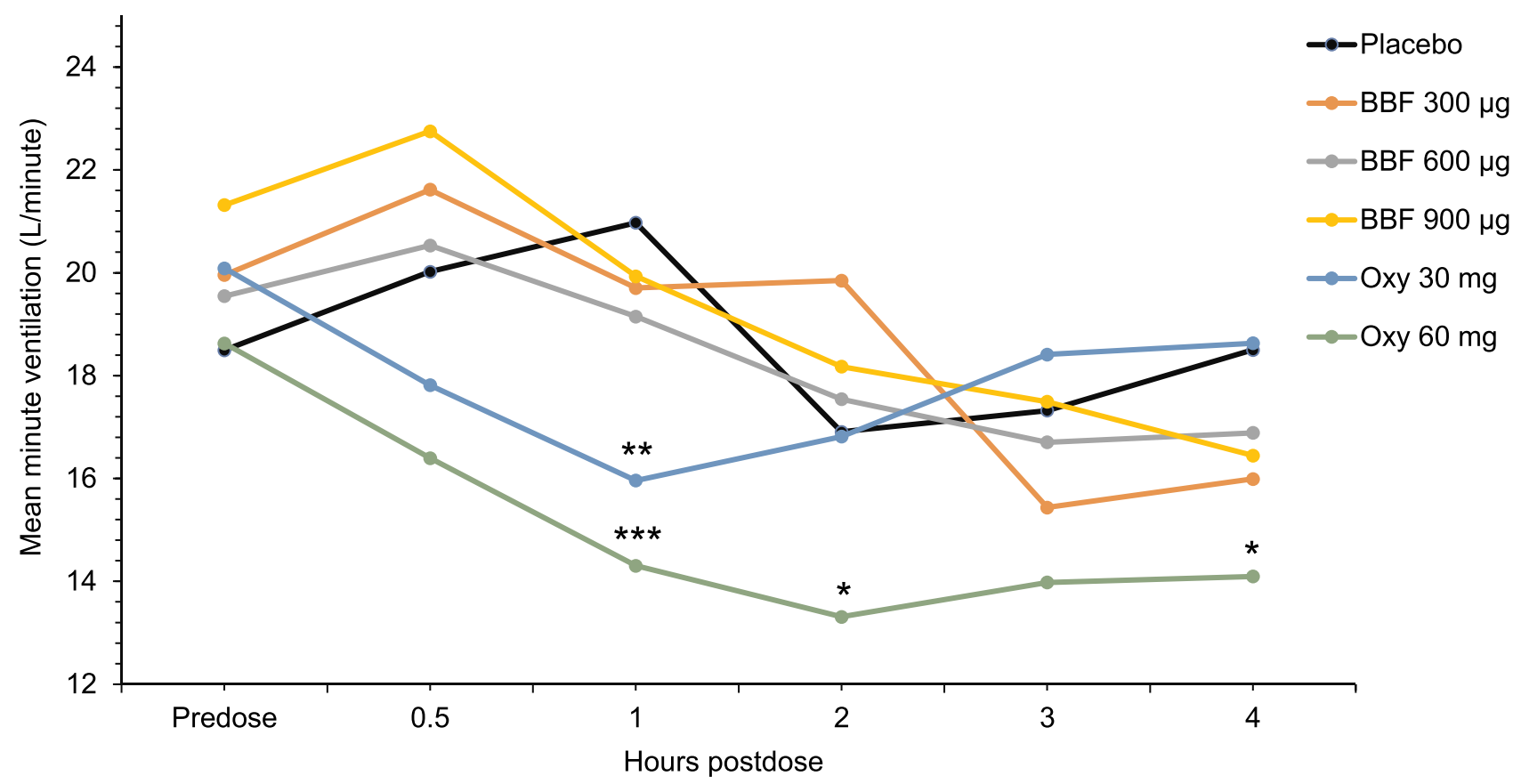

Figure 6 Effect of Buprenorphine Buccal Film and Oxycodone Hydrochloride on Minute Ventilation. Effect of each drug treatment on respiratory drive: mean minute ventilation over time. In the partial completer population $(n=16)$, mean minute ventilation for $B B F$ was not significantly different from placebo at any time point. $* p<0.05$, $* * p<0.01$, **** $p<0.001$.

Notes: Reprinted by permission from Springer Nature, Adv Ther, Webster LR, Hansen E, Cater J, Smith T, Phase A. I placebo-controlled trial comparing the effects of buprenorphine buccal film and oral oxycodone hydrochloride administration on respiratory drive. Copyright 2020;37(II):4685-4696. ${ }^{54}$

Abbreviations: BBF, buprenorphine buccal film; Oxy, oxycodone.

patients each, but in a postmarketing survey of 13,179 patients receiving transdermal buprenorphine, only 1 $(0.01 \%)$ patient experienced respiratory depression. ${ }^{67}$ This is approximately 80 times less than what was observed in a separate study of transdermal fentanyl. ${ }^{68}$ While IV buprenorphine may cause some respiratory depression, studies have demonstrated that it plateaus with a ceiling effect, whereas conventional opioids such as fentanyl do not. ${ }^{11,12}$ Sedatives such as benzodiazepines and alcohol increase the risk of respiratory depression, and benzodiazepines are not recommended to be prescribed in combination with any opioids. ${ }^{1}$ Because the risk of respiratory depression appears to be lower with buprenorphine than with conventional opioids, an overdose may be less likely to result in a fatality.

In addition to a decreased risk of respiratory depression, other tolerability factors like constipation are more favorable with buprenorphine. Constipation rates for ER full $\mu$-opioid receptor agonists range from $8 \%$ to $23 \%,{ }^{69-72}$ while constipation was reported in only $4 \%$ of patients receiving buprenorphine buccal film and in $13 \%$ of patients receiving transdermal buprenorphine. ${ }^{20,21}$ In a postmarketing surveillance study, 128 (1\%) of 13,179 patients receiving transdermal buprenorphine experienced constipation. ${ }^{67}$ Opioid-induced constipation is associated with increased economic burden and reduced quality of life, so buprenorphine may be preferable to conventional opioids when considering this adverse event. ${ }^{73}$ In addition, a comparison of adverse events reported in clinical trials for buprenorphine buccal film and ER formulations of oxycodone, hydromorphone, and oxymorphone showed that the proportion of patients who experienced nausea, vomiting, constipation, headache, dizziness, somnolence, anxiety, and dry mouth was lower with buprenorphine buccal film than with conventional opioids (Figure 7).

Unlike with conventional opioids, additional benefits of buprenorphine due to its unique metabolism include suitability for use in patients requiring concomitant medications, those with renal or hepatic impairment, and the elderly. ${ }^{14}$ Most patients with OUD have been found to also have chronic pain, and among them, the majority had chronic pain before their first OUD diagnosis, making appropriate treatment in this subset of patients essential. ${ }^{74}$ Patients with comorbid chronic pain and OUD have reported satisfaction with buprenorphine treatment. $^{75}$ Also, buprenorphine is not immunosuppressive, ${ }^{76,77}$ does not negatively impact the 


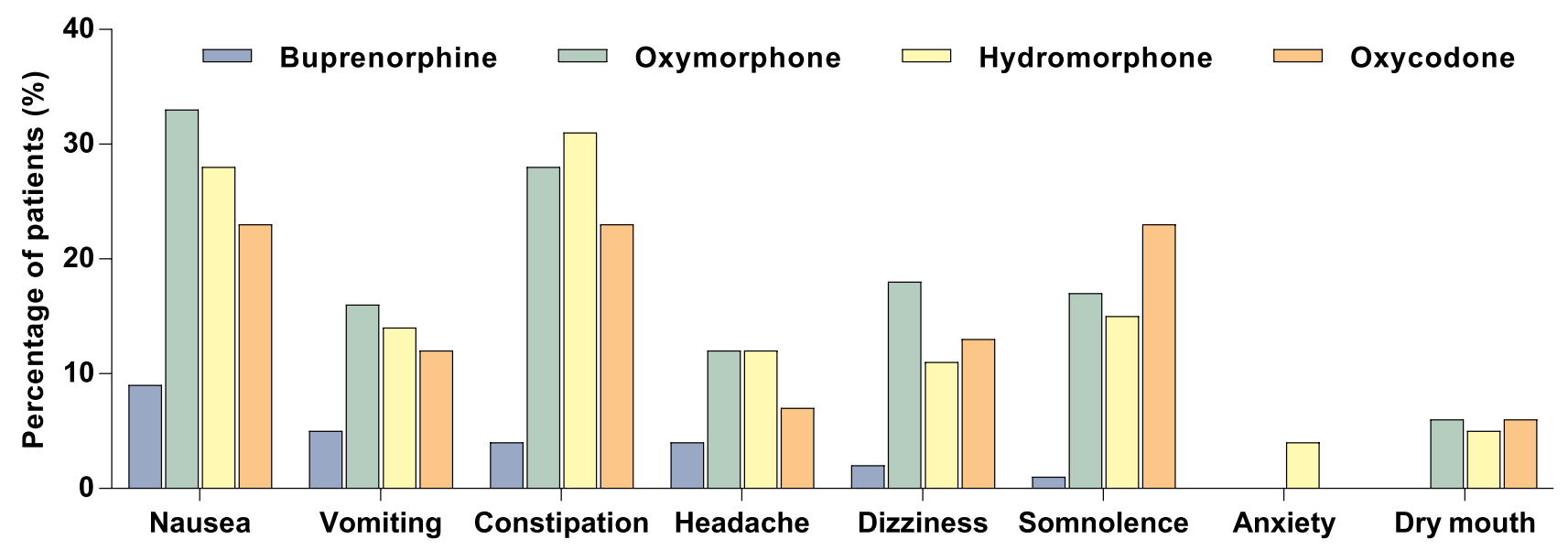

Figure 7 Adverse Events Reported in Clinical Trials of Buprenorphine Buccal Film Compared With Conventional Opioids for Chronic Pain. The percentage of patients who reported adverse events in clinical trials for buprenorphine buccal film ${ }^{21}$ compared with those reported for extended-release formulations of oxymorphone, ${ }^{87}$ hydromorphone, ${ }^{88}$ and oxycodone. ${ }^{69}$

Notes: Copyright @2019. Dove Medical Press. Adapted from Pergolizzi JV, Jr., Raffa RB. Safety and efficacy of the unique opioid buprenorphine for the treatment of chronic pain. J Pain Res. 2019;12:3299-3317.

hypothalamic-pituitary-adrenal pathway, ${ }^{78-80}$ and may reduce anxiety and depression. ${ }^{81-84}$

Overall, the safety data and additional benefits of buprenorphine suggest that it has a lower risk of adverse events compared with conventional opioids, most notably with respiratory depression. However, all opioids, including buprenorphine, carry the risk of adverse events and addiction potential, depending on the dose. Therefore, careful consideration should be given to the risks and benefits of each opioid before prescribing. Health care providers should consider using one or more opioid risk screening tools before the initiation of any opioid therapy. ${ }^{85,86}$

\section{Conclusions}

Clinical safety and efficacy data in this narrative review suggest that buprenorphine may be a more tolerable alternative with equivalent or superior analgesia to conventional opioids for patients with pain. IV buprenorphine has been the most extensively studied formulation and is FDA-approved for acute pain, while the transdermal patch and buccal film are FDA-approved for chronic pain. The transdermal patch has demonstrated efficacy for chronic pain with once-weekly dosing. Health care providers may find that the buprenorphine buccal film formulation has favorable bioavailability, available doses, efficacy, adverse event profile, and benefit-risk assessments for the treatment of chronic pain. Clinicians should always consider the benefits and risks of various therapeutic options for pain management and are encouraged to explore their unique aspects, long-term clinical impact, and individual patient needs.

\section{Acknowledgments}

Professional writing and editorial support was provided by MedLogix Communications, LLC, Itasca, Illinois, under the direction of the authors and was funded by BioDelivery Sciences International, Inc. No author received financial compensation for writing or directing the content of this manuscript.

\section{Author Contributions}

All authors contributed to the conception and design of the manuscript, analysis and interpretation of data, and critical evaluation of the manuscript for scientific accuracy and intellectual content; approved the final manuscript for publication; and agreed to be accountable for all aspects of the work.

\section{Disclosure}

$\mathrm{MH}$ has served on advisory boards for BioDelivery Sciences International, Inc. and was principal investigator for multiple buprenorphine trials. MG has served on advisory boards for Daiichi Sankyo, Inc. RBR is the CSO of Neumentum Inc.; cofounder of CaRafe Drug Innovation, LLC; and cofounder of Enalare Therapeutics Inc. The authors report no other conflicts of interest in this work.

\section{References}

1. US Department of Health \& Human Services. Pain management best practices inter-agency task force report: updates, gaps, inconsistencies, and recommendations 9, 2019. Available from: https://www.hhs.gov/ ash/advisory-committees/pain/reports/index.html. Accessed July 11, 2020. 
2. Dahlhamer J, Lucas J, Zelaya C, et al. Prevalence of chronic pain and high-impact chronic pain among adults - United States, 2016. MMWR Morb Mortal Wkly Rep. 2018;67(36):1001-1006. doi:10.15585/ mmwr.mm6736a2

3. Rosenquist R. Use of opioids in the management of chronic noncancer pain. In: Aronson $\mathrm{MD}$, Crowley $\mathrm{M}$, editors. UpToDate. Waltham, MA: UpToDate; 2020.

4. National Institute on Drug Abuse. Opioid overdose crisis. 2020. Available from: https://www.drugabuse.gov/drug-topics/opioids/ opioid-overdose-crisis. Accessed September 16, 2020.

5. Litman RS. Abuse deterrent opioids. In: Fishman S, Crowley M, editors. UpToDate. Waltham, MA: UpToDate; 2020.

6. Haley DF, Saitz R. The opioid epidemic during the COVID-19 pandemic. JAMA. 2020. doi:10.1001/jama.2020.18543

7. Pergolizzi JV Jr., Raffa RB. Safety and efficacy of the unique opioid buprenorphine for the treatment of chronic pain. J Pain Res. 2019;12:3299-3317. doi:10.2147/JPR.S231948

8. Dahan A, Cowan A, Foley K, et al. Buprenorphine - The Unique Opioid Analgesic. Pharmacology and Clinical Application. Thieme Verlagsgruppe.

9. Gudin J, Fudin J. A narrative pharmacological review of buprenorphine: a unique opioid for the treatment of chronic pain. Pain Ther. 2020;9(1):41-54. doi:10.1007/s40122-019-00143-6

10. Dahan A, Yassen A, Bijl H, et al. Comparison of the respiratory effects of intravenous buprenorphine and fentanyl in humans and rats Br J Anaesth. 2005;94(6):825-834. doi:10.1093/bja/aei145

11. Dahan A, Yassen A, Romberg R, et al. Buprenorphine induces ceiling in respiratory depression but not in analgesia. Br J Anaesth. 2006;96 (5):627-632. doi:10.1093/bja/ael051

12. Kress HG. Clinical update on the pharmacology, efficacy and safety of transdermal buprenorphine. Eur J Pain. 2009;13(3):219-230. doi:10.1016/j.ejpain.2008.04.011

13. Pergolizzi J, Aloisi AM, Dahan A, et al. Current knowledge of buprenorphine and its unique pharmacological profile. Pain Pract. 2010;10(5):428-450. doi:10.1111/j.1533-2500.2010.00378.x

14. Pergolizzi J, Boger RH, Budd K, et al. Opioids and the management of chronic severe pain in the elderly: consensus statement of an International Expert Panel with focus on the six clinically most often used World Health Organization Step III opioids (buprenorphine, fentanyl, hydromorphone, methadone, morphine, oxycodone). Pain Pract. 2008;8(4):287-313. doi:10.1111/j.15332500.2008.00204.x

15. Walsh SL, Preston KL, Bigelow GE, Stitzer ML. Acute administration of buprenorphine in humans: partial agonist and blockade effects. J Pharmacol Exp Ther. 1995;274(1):361-372.

16. Yassen A, Olofsen E, Romberg R, Sarton E, Danhof M, Dahan A. Mechanism-based pharmacokinetic-pharmacodynamic modeling of the antinociceptive effect of buprenorphine in healthy volunteers. Anesthesiology. 2006;104(6):1232-1242. doi:10.1097/00000542200606000-00019

17. Carlezon WA Jr., Krystal AD. Kappa-opioid antagonists for psychiatric disorders: from bench to clinical trials. Depress Anxiety. 2016;33 (10):895-906. doi:10.1002/da.22500

18. Kumar R, Viswanath O, Saadabadi A.Buprenorphine. [Updated 2020 Feb 27].In:StatPearls [Internet].Treasure Island (FL):StatPearls Publishing;2020.Jan-.Available from.https:/www.ncbi.nlm.nih.gov/ books/NBK459126/.Accessed May 7, 2021.

19. Buprenex. Package insert. Indivior, Inc.; 2019.

20. Butrans. Package insert. Purdue Pharma LP; 2019.

21. Belbuca. Package insert. BioDelivery Sciences International, Inc.; 2019

22. Sublocade. Package insert. Indivior, Inc.; 2020.

23. Subutex. Package insert. Bryant Ranch Prepack; 2009.

24. Probuphine. Package insert. Titan Pharmaceuticals, Inc.; 2019.

25. Braeburn. Pipeline. Available from: https://braeburnrx.com/pipeline/. Accessed October 19, 2020.
26. Nath RP, Upton RA, Everhart ET, et al. Buprenorphine pharmacokinetics: relative bioavailability of sublingual tablet and liquid formulations. J Clin Pharmacol. 1999;39(6):619-623. doi:10.1177/ 00912709922008236

27. Schmidt-Hansen M, Bromham N, Taubert M, Arnold S, Hilgart JS. Buprenorphine for treating cancer pain. Cochrane Database Syst Rev. 2015;3:CD009596.

28. Okkerse P, Alvarez-Jimenez R, Hay JL, et al. No evidence of potentiation of buprenorphine by milnacipran in healthy subjects using a nociceptive test battery. Eur J Pain. 2017;21(3):494-506. doi:10.1002/ejp.943

29. Bradley JP. A comparison of morphine and buprenorphine for analgesia after abdominal surgery. Anaesth Intensive Care. 1984;12 (4):303-310. doi:10.1177/0310057X8401200403

30. Chang KY, Chang WK, Chang WL, et al. Comparison of intravenous patient-controlled analgesia with buprenorphine versus morphine after lumbar spinal fusion-a prospective randomized clinical trial. Acta Anaesthesiol Taiwan. 2006;44(3):153-159.

31. Kay B. A double-blind comparison of morphine and buprenorphine in the prevention of pain after operation. Br J Anaesth. 1978;50 (6):605-609. doi:10.1093/bja/50.6.605

32. Maunuksela EL, Korpela R, Olkkola KT. Double-blind, multiple-dose comparison of buprenorphine and morphine in postoperative pain of children. Br J Anaesth. 1988;60(1):48-55. doi: $10.1093 / \mathrm{bja} / 60.1 .48$

33. Mercieri M, Palmisani S, De Blasi RA, et al. Low-dose buprenorphine infusion to prevent postoperative hyperalgesia in patients undergoing major lung surgery and remifentanil infusion: a double-blind, randomized, active-controlled trial. $\mathrm{Br} J$ Anaesth. 2017;119(4):792-802. doi:10.1093/bja/aex174

34. Oifa S, Sydoruk T, White I, et al. Effects of intravenous patient-controlled analgesia with buprenorphine and morphine alone and in combination during the first 12 postoperative hours: a randomized, double-blind, four-arm trial in adults undergoing abdominal surgery. Clin Ther. 2009;31(3):527-541. doi:10.1016/j. clinthera.2009.03.018

35. Rabinov M, Rosenfeldt FL, McLean AJ. A double-blind comparison of the relative efficacy, side effects and cost of buprenorphine and morphine in patients after cardiac surgery. Aust N Z J Surg. 1987;57 (4):227-231. doi:10.1111/j.1445-2197.1987.tb01345.x

36. Raffa RB, Haidery M, Huang HM, et al. The clinical analgesic efficacy of buprenorphine. J Clin Pharm Ther. 2014;39(6):577-583. doi:10.1111/jcpt.12196

37. Beltrutti D, Niv D, Ben-Abraham R, Di Santo S, Weinbroum AA. Late antinociception and lower untoward effects of concomitant intrathecal morphine and intravenous buprenorphine in humans. J Clin Anesth. 2002;14(6):441-446. doi:10.1016/s0952-8180(02) 00397-5

38. Jakobs R, Adamek MU, von Bubnoff AC, Riemann JF. Buprenorphine or procaine for pain relief in acute pancreatitis. A prospective randomized study. Scand J Gastroenterol. 2000;35 (12):1319-1323. doi:10.1080/003655200453692

39. Cote J, Montgomery L. Sublingual buprenorphine as an analgesic in chronic pain: a systematic review. Pain Med. 2014;15(7):1171-1178. doi: $10.1111 /$ pme. 12386

40. Malinoff HL, Barkin RL, Wilson G. Sublingual buprenorphine is effective in the treatment of chronic pain syndrome. Am J Ther. 2005;12(5):379-384. doi:10.1097/01.mjt.0000160935.62883.ff

41. Edge WG, Cooper GM, Morgan M. Analgesic effects of sublingual buprenorphine. Anaesthesia. 1979;34(5):463-467. doi:10.1111/ j.1365-2044.1979.tb06325.x

42. Gaitini L, Moskovitz B, Katz E, Vaisberg A, Vaida S, Nativ O. Sublingual buprenorphine compared to morphine delivered by a patient-controlled analgesia system as postoperative analgesia after prostatectomy. Urol Int. 1996;57(4):227-229. doi:10.1159/ 000282920 
43. Masson AH. Sublingual buprenorphine versus oral dihydrocodeine in post-operative pain. J Int Med Res. 1981;9(6):506-510. doi:10.1177/ 030006058100900614

44. Steiner DJ, Sitar S, Wen W, et al. Efficacy and safety of the seven-day buprenorphine transdermal system in opioid-naive patients with moderate to severe chronic low back pain: an enriched, randomized, double-blind, placebo-controlled study. J Pain Symptom Manage. 2011;42(6):903-917. doi:10.1016/j.jpainsymman.2011.04.006

45. Corli O, Floriani I, Roberto A, et al. Are strong opioids equally effective and safe in the treatment of chronic cancer pain? A multicenter randomized Phase IV 'real life' trial on the variability of response to opioids. Ann Oncol. 2016;27(6):1107-1115. doi:10.1093/annonc/mdw097

46. Desai SN, Badiger SV, Tokur SB, Naik PA. Safety and efficacy of transdermal buprenorphine versus oral tramadol for the treatment of post-operative pain following surgery for fracture neck of femur: a prospective, randomised clinical study. Indian J Anaesth. 2017;61 (3):225-229. doi:10.4103/ija.IJA_208_16

47. Kim HJ, Ahn HS, Nam Y, Chang BS, Lee CK, Yeom JS. Comparative study of the efficacy of transdermal buprenorphine patches and prolonged-release tramadol tablets for postoperative pain control after spinal fusion surgery: a prospective, randomized controlled non-inferiority trial. Eur Spine J. 2017;26(11):2961-2968. doi:10.1007/s00586-017-5213-5

48. Lee JH, Kim JH, Kim JH, et al. Efficacy and safety of transdermal buprenorphine versus oral tramadol/acetaminophen in patients with persistent postoperative pain after spinal surgery. Pain Res Manag. 2017;2017:2071494. doi:10.1155/2017/2071494

49. Gimbel J, Spierings EL, Katz N, Xiang Q, Tzanis E, Finn A. Efficacy and tolerability of buccal buprenorphine in opioid-experienced patients with moderate to severe chronic low back pain: results of a Phase 3, enriched enrollment, randomized withdrawal study. Pain. 2016;157(11):2517-2526. doi:10.1097/j.pain.0000000000000670

50. Hale M, Urdaneta V, Kirby MT, Xiang Q, Rauck R. Long-term safety and analgesic efficacy of buprenorphine buccal film in patients with moderate-to-severe chronic pain requiring around-the-clock opioids. J Pain Res. 2017;10:233-240. doi:10.2147/JPR.S120170

51. Rauck RL, Potts J, Xiang Q, Tzanis E, Finn A. Efficacy and tolerability of buccal buprenorphine in opioid-naive patients with moderate to severe chronic low back pain. Postgrad Med. 2016;128 (1):1-11. doi:10.1080/00325481.2016.1128307

52. Zimmerman A Conversion of CII opioid to buprenorphine buccal film: a retrospective analysis [304]. AAPM 36th Annual Meeting Scientific Poster Abstracts. 2020:31.

53. Priestley T, Chappa AK, Mould DR, et al. Converting from Transdermal to buccal formulations of buprenorphine: a pharmacokinetic meta-model simulation in healthy volunteers. Pain Med. 2018;19(10):1988-1996. doi:10.1093/pm/pnx235

54. Webster LR, Hansen E, Cater J, Smith T, Phase A. I placebo-controlled trial comparing the effects of buprenorphine buccal film and oral oxycodone hydrochloride administration on respiratory drive. $A d v$ Ther. 2020;37(11):4685-4696. doi:10.1007/s12325-020-01481-0

55. Opioid Oral Morphine Milligram Equivalent (MME) Conversion Factors. Available from: https://www.cms.gov/Medicare/Prescription-Drugcoverage/PrescriptionDrugCovContra/Downloads/Opioid-Morphine-EQ -Conversion-Factors-Aug-2017.pdf. Accessed May 7, 2021.

56. Corli O, Montanari M, Deandrea S, Greco MT, Villani W, Apolone G. An exploratory analysis on the effectiveness of four strong opioids in patients with cancer pain. Pain Med. 2012;13 (7):897-907. doi:10.1111/j.1526-4637.2012.01408.x

57. Karlsson M, Berggren AC. Efficacy and safety of low-dose transdermal buprenorphine patches $(5,10$, and $20 \mathrm{microg} / \mathrm{h})$ versus prolonged-release tramadol tablets $(75,100,150$, and $200 \mathrm{mg}$ ) in patients with chronic osteoarthritis pain: a 12-week, randomized, open-label, controlled, parallel-group noninferiority study. Clin Ther. 2009;31(3):503-513. doi:10.1016/j.clinthera.2009.03.001
58. Leng X, Li Z, Lv H, et al. Effectiveness and safety of transdermal buprenorphine versus sustained-release tramadol in patients with moderate to severe musculoskeletal pain: an 8-week, randomized, double-blind, double-dummy, multicenter, active-controlled, noninferiority study. Clin J Pain. 2015;31(7):612-620. doi:10.1097/ AJP.0000000000000144

59. Hale M, Khan A, Kutch M, Once-daily LS. OROS hydromorphone ER compared with placebo in opioid-tolerant patients with chronic low back pain. Curr Med Res Opin. 2010;26(6):1505-1518. doi:10.1185/03007995.2010.484723

60. Hale ME, Ahdieh H, Ma T, Rauck R, Oxymorphone ER Study Group. Efficacy and safety of OPANA ER (oxymorphone extended release) for relief of moderate to severe chronic low back pain in opioid-experienced patients: a 12-week, randomized, double-blind, placebo-controlled study. J Pain. 2007;8(2):175-184. doi:10.1016/j. jpain.2006.09.011

61. Rauck RL, Nalamachu S, Wild JE, et al. Single-entity hydrocodone extended-release capsules in opioid-tolerant subjects with moderate-to-severe chronic low back pain: a randomized double-blind, placebo-controlled study. Pain Med. 2014;15 (6):975-985. doi:10.1111/pme.12377

62. Lazaridou A, Paschali M, Edwards RR, Gilligan C. Is buprenorphine effective for chronic pain? a systematic review and meta-analysis. Pain Med. 2020. doi:10.1093/pm/pnaa089

63. US Department of Justice. Drug Enforcement Administration. Drugs of abuse. 2020. Available from: https://www.dea.gov/sites/default/ files/2020-04/Drugs\%20of\%20Abuse\%202020-Web\%20Version508\%20compliant-4-24-20_0.pdf. Accessed March 29, 2021.

64. Wightman RS, Perrone J, Scagos R, Krieger M, Nelson LS, Marshall BDL. Opioid overdose deaths with buprenorphine detected in postmortem toxicology: a retrospective analysis. $J$ Med Toxicol. 2020. doi:10.1007/s13181-020-00795-3

65. Robinson SE. Buprenorphine: an analgesic with an expanding role in the treatment of opioid addiction. CNS Drug Rev. 2002;8(4):377-390. doi:10.1111/j.1527-3458.2002.tb00235.x

66. Walsh SL, Eissenberg T. The clinical pharmacology of buprenorphine: extrapolating from the laboratory to the clinic. Drug Alcohol Depend. 2003;70(suppl 2):S13-27. doi:10.1016/s0376-8716(03) 00056-5

67. Griessinger N, Sittl R, Likar R. Transdermal buprenorphine in clinical practice-a post-marketing surveillance study in 13,179 patients. Curr Med Res Opin. 2005;21(8):1147-1156. doi:10.1185/ 030079905X53315

68. Radbruch L, Sabatowski R, Petzke F, Brunsch-Radbruch A, Grond S, Lehmann KA. Transdermal fentanyl for the management of cancer pain: a survey of 1005 patients. Palliat Med. 2001;15(4):309-321. doi:10.1191/026921601678320296

69. Oxycontin. Package insert. Purdue Pharma L.P.; 2021.

70. Zohydro. Package insert. Pernix Therapeutics, LLC; 2019.

71. Kadian. Package insert. Allergan USA, Inc.; 2019.

72. Nucynta ER. Package insert. Depomed, Inc; 2021.

73. Wan Y, Corman S, Gao X, Liu S, Patel H, Mody R. Economic burden of opioid-induced constipation among long-term opioid users with noncancer pain. Am Health Drug Benefits. 2015;8 (2):93-102.

74. Hser YI, Mooney LJ, Saxon AJ, Miotto K, Bell DS, Huang D. Chronic pain among patients with opioid use disorder: results from electronic health records data. $J$ Subst Abuse Treat. 2017;77:26-30. doi:10.1016/j.jsat.2017.03.006

75. Streltzer J, Davidson R, Goebert D. An observational study of buprenorphine treatment of the prescription opioid dependent pain patient. Am J Addict. 2015;24(4):357-361. doi:10.1111/ajad.12198

76. Davis MP. Twelve reasons for considering buprenorphine as a frontline analgesic in the management of pain. J Support Oncol. 2012;10(6):209-219. doi:10.1016/j.suponc.2012.05.002 
77. Budd K. Pain management: is opioid immunosuppression a clinical problem? Biomed Pharmacother. 2006;60(7):310-317. doi:10.1016/j. biopha.2006.06.015

78. Hallinan R, Byrne A, Agho K, McMahon CG, Tynan P, Attia J. Hypogonadism in men receiving methadone and buprenorphine maintenance treatment. Int $J$ Androl. 2009;32(2):131-139. doi:10.1111/j.1365-2605.2007.00824.x

79. Hallinan R, Byrne A, Agho K, McMahon C, Tynan P, Attia J. Erectile dysfunction in men receiving methadone and buprenorphine maintenance treatment. J Sex Med. 2008;5(3):684-692. doi:10.1111/ j.1743-6109.2007.00702.x

80. Aurilio C, Ceccarelli I, Pota V, et al. Endocrine and behavioural effects of transdermal buprenorphine in pain-suffering women of different reproductive ages. Endocr J. 2011;58(12):1071-1078. doi:10.1507/endocrj.ej11-0095

81. Karp JF, Butters MA, Begley AE, et al. Safety, tolerability, and clinical effect of low-dose buprenorphine for treatment-resistant depression in midlife and older adults. J Clin Psychiatry. 2014;75 (8):e785-93. doi:10.4088/JCP.13m08725
82. Bodkin JA, Zornberg GL, Lukas SE, Cole JO. Buprenorphine treatment of refractory depression. J Clin Psychopharmacol. 1995;15 (1):49-57. doi:10.1097/00004714-199502000-00008

83. Serafini G, Adavastro G, Canepa G, et al. The efficacy of buprenorphine in major depression, treatment-resistant depression and suicidal behavior: a systematic review. Int J Mol Sci. 2018;19:8. doi:10.3390/ ijms 19082410

84. Ahmadi J, Jahromi MS. Anxiety treatment of opioid dependent patients with buprenorphine: a randomized, double-blind, clinical trial. Indian J Psychol Med. 2017;39(4):445-449. doi:10.4103/02537176.211765

85. Ducharme J, Moore S. Opioid use disorder assessment tools and drug screening. Mo Med. 2019;116(4):318-324.

86. Garofoli M. Spuds, screenings \& safety: from chips to opioids. PAINWeek. Available from: https://www.painweek.org/media/jour nal/spuds-screenings-safety-chips-opioids. Accessed October 19, 2020 .

87. Opana ER. Package insert. Endo Pharmaceuticals, Inc; 2019.

88. Exalgo. Package insert. Mallinckrodt; 2019.

\section{Publish your work in this journal}

The Journal of Pain Research is an international, peer reviewed, open access, online journal that welcomes laboratory and clinical findings in the fields of pain research and the prevention and management of pain. Original research, reviews, symposium reports, hypothesis formation and commentaries are all considered for publication. The manuscript management system is completely online and includes a very quick and fair peer-review system, which is all easy to use. Visit http:// www.dovepress.com/testimonials.php to read real quotes from published authors. 